www.scielo.cl

\title{
Pain insensitivity in a child with a de novo interstitial deletion of the long arm of the chromosome 4. Case report
}

\author{
Insensibilidad al dolor en un niño con una deleción intersticial de novo \\ del brazo largo del cromosoma 4. Caso Clínico
}

\author{
Marco Cascella ${ }^{\mathrm{a}}$, María Rosaria Muzio ${ }^{\mathrm{b}}$
}

aDivision of Anesthesia, Department of Anesthesia and Pain Medicine, Istituto Nazionale Tumori "Fondazione G. Pascale". IRCCS, Naples, Italy

${ }^{b}$ Division of Infantile Neuropsychiatry, UOMI-Maternal and Infant Health, ASL NA3/Sud, NA, Italy

Recibido el 16 de septiembre de 2016; aceptado el 21 de octubre de 2016

\begin{abstract}
Introduction. Terminal and interstitial deletions of the distal segment of the long arm of chromosome $4(\mathrm{Cr} 4 \mathrm{q} \mathrm{del})$ are not common genetic disorders. The severity of the phenotype is correlated with the size of the deletion because small deletions have little clinical impact, whereas large deletions are usually associated with multiple congenital anomalies, postnatal growth failure, and moderate to severe intellectual disability. Alteration in pain tolerance has not been included among these features, also in case of large deletions. The purpose of this report is to document a case of a child affected by interstitial $\mathrm{Cr} 4 \mathrm{q}$ del, expressing pain insensitivity as clinical feature not previously described. We also offer a discussion on genetic disorders featuring pain insensitivity/indifference. Case report. A Caucasian girl aged 12 came to our observation for a developmental delay with multiple congenital abnormalities and moderate intellectual disability (IQ 47). A de novo interstitial $\mathrm{Cr} 4$ del between band q31.3 and q32.2 (Cr4 del q31.3 to q32.2) was found. The child also expresses no evidence of pain perception to injures which normally evoke pain. Consequently, she is affected by severe disability caused by painless injuries and self-injurious behaviours, such as excessive self-rubbing and scratching. The neurological examination manifested high pain threshold with preserved tactile sensitivity. Conclusions. This is the first report of pain insensitivity in a patient with a specific genetic deletion involving the interstitial region of the distal long arm of $\mathrm{Cr} 4$. Moreover, this report could serve as a useful model to better understand mechanisms of pain perception and its modulation.
\end{abstract}

\section{Keywords:}

Pain Assessment;

Pain Insensitivity;

Pain Perception;

Chromosome 4;

Microdeletion;

Pain Threshold;

Channelopathies;

Intellectual Disability. 


\section{Introduction}

Terminal and interstitial deletions of the distal segment of the long arm of chromosome $4(\mathrm{Cr} 4 \mathrm{q}$ del) are not common genetic disorders with an estimated incidence of $1 / 100,000^{1}$. The first report was presented by Ockey et al. in $1967^{2}$, whereas in 1992 a large interstitial Cr4q del with breakpoints at q31.22 to q34.2 was described by Sarda and colleagues ${ }^{3}$. In order to establish a genotype-phenotype correlation, the severity of the phenotype is correlated with the size of the deletion. Thus, several reports suggested that small terminal, or interstitial, distal Cr4q del involving bands $4 \mathrm{q} 34$ and $4 q 35$ seems to have little clinical impact, consisting in little facial dysmorphism and mild, or absent, intellectual disability (ID) ${ }^{4}$, and Yakut et al. ${ }^{5}$ reported a case of a familial interstitial 4q35 deletion with no discernible phenotypic effects. On the other hand, a relatively constant phenotype can be recognised in $4 \mathrm{q} 31$ to qter deletion. These features include craniofacial dysmorphisms, such as hypertelorism, short, upturned nose, depressed nasal bridge, cleft palate, Pierre Robin sequence, micrognathia, and external ear abnormalities, combined with other major physical findings, such as abnormalities of the fingers (absent digits, clinodactyly, camptodactyly), abnormal thumb or hallux implantation, tapering fingers, pointed or duplicated fifth nail, abnormal palmar creases, congenital heart defects, and genitourinary malformations. Moreover, progress is marked by postnatal growth failure and moderate to severe ID.

Alteration in pain tolerance has not been included among these features, also in case of large deletions. Conversely, pain insensitivity or high pain tolerance may be experienced in several genetic disorders, especially in monogenic alterations, such as channelopathies $^{6}$, or in other disorders involving mutations in genes encoding receptors or modulators (table 1).

Table 1. Pain features in several genetic disorders

\begin{tabular}{|c|c|c|c|}
\hline Genetic disorder & Pain features & Comments & Reference(s) \\
\hline \multicolumn{4}{|l|}{ Genetic channelopathies } \\
\hline $\begin{array}{l}\text { Congenital 'indifference' } \\
\text { to pain }(\mathrm{CIP})\end{array}$ & $\begin{array}{l}\text { Absence of reaction to painful } \\
\text { stimuli }\end{array}$ & $\begin{array}{l}\text { Recessive mutations in the SCN9A gene } \\
\text { encoding the Nav1.7 channel (chromosome } \\
2 \mathrm{q} 24 \text { ) }\end{array}$ & $\begin{array}{l}\text { Bennett DL et al } 20 \\
\text { Cox JJ et } \mathrm{al}^{21}\end{array}$ \\
\hline $\begin{array}{l}\text { Paroxysmal extreme pain } \\
\text { disorder (PEPD) }\end{array}$ & $\begin{array}{l}\text { Paroxysmal attacks of pain } \\
\text { involving the lower body (eg, } \\
\text { rectum), eyes, and jaw often } \\
\text { accompanied by flushing of } \\
\text { the affected site and other } \\
\text { autonomic disturbances }\end{array}$ & $\begin{array}{l}\text { Autosomal dominant mutation in the SCN9A } \\
\text { gene encoding for the alpha subunit of } \\
\text { NaV1.7 }\end{array}$ & Fertleman $\mathrm{CR}$ et $\mathrm{al}^{24}$ \\
\hline Primary erythermalgia & $\begin{array}{l}\text { Attacks of neuropathic pain } \\
\text { and erithema in the hands } \\
\text { and feet triggered by mild } \\
\text { warming stimuli }\end{array}$ & $\begin{array}{l}\text { Autosomal dominant mutation in the SCN9A } \\
\text { gene encoding for several regions of Nav1.7, } \\
\text { such as the fourth domain }\end{array}$ & $\begin{array}{l}\text { Cregg } \mathrm{R} \text { et } \mathrm{al}^{23} \\
\text { Eberhardt } \mathrm{M} \text { et } \mathrm{al}^{25}\end{array}$ \\
\hline $\begin{array}{l}\text { Familial episodic pain } \\
\text { syndrome }\end{array}$ & $\begin{array}{l}\text { Episodes of debilitating upper } \\
\text { body pain, triggered by fasting } \\
\text { and physical stress }\end{array}$ & $\begin{array}{l}\text { Autosomal dominant mutation in the TRPA1 } \\
\text { gene on chromosome } 8 q 13\end{array}$ & Kremeyer B et al ${ }^{\mid 31}$ \\
\hline \multicolumn{4}{|c|}{ Disorders other than channelopathies } \\
\hline $\begin{array}{l}\text { Congenital insensitivity to } \\
\text { pain with anhidrosis (CIPA) }\end{array}$ & $\begin{array}{l}\text { Absence of reaction to } \\
\text { noxious or painful stimuli }\end{array}$ & $\begin{array}{l}\text { Autosomal recessive disease caused by } \\
\text { a mutation in TRKA gene located on } \\
\text { chromosome } 1 \text { ( } 1 \text { q21-q22) encoding the high- } \\
\text { affinity tyrosine kinase receptor NTRK1 for } \\
\text { nerve growth factor (NGF) }\end{array}$ & $\begin{array}{l}\text { Pérez-López LM et al }{ }^{14} \\
\text { Indo } Y^{15}\end{array}$ \\
\hline $\begin{array}{l}\text { Hereditary sensory and } \\
\text { autonomic neuropathy } \\
\text { type V (HSAN5) }\end{array}$ & Loss of pain perception & Mutation in the NGF gene & $\begin{array}{l}\text { Carvalho OP et al }{ }^{16} \\
\text { Einarsdottir } \mathrm{E} \text { et al }{ }^{17}\end{array}$ \\
\hline \multicolumn{4}{|l|}{ Complex genetic disorders } \\
\hline Angelman syndrome & High pain threshold & $\begin{array}{l}\text { Deletion or mutation in maternal chromosome } \\
15 \text { region containing the UBE3A gene }\end{array}$ & Artigas-Pallarés J7 \\
\hline Prader-Willi Syndrome & High pain threshold & $\begin{array}{l}\text { Paternal } 15 q 11-q 13 \text { deletion or maternal } \\
\text { uniparental disomy } 15\end{array}$ & Angulo MA et $a^{8}$ \\
\hline $\begin{array}{l}\text { Chromosome } 15 q \text { duplication } \\
\text { syndrome }\end{array}$ & High pain tolerance & $\begin{array}{l}\text { Pain disorder mare evident in the isodicentric } \\
\text { mutations rather than in the interstitial forms }\end{array}$ & Luchsinger et al ${ }^{9}$ \\
\hline
\end{tabular}


However, the mechanism of nociception, and the role of the genes encoding for receptors and mediators, has not yet been fully explained. For instance, little is known on epigenetic regulators that control the development of sensory neurons and the function of nociceptors. Thus, complex genetic disorders, such as deletions or duplications, can include among their features alteration in pain sensitivity, but the exact genotypephenotype correlation is misunderstood. For instance, Artigas-Pallarés et colleagues found a high percentage of patients with Angelman syndrome manifesting a high resistance to pain $(67 \%)^{7}$, whereas a high pain threshold is a very common symptom in Prader-Willi syndrome, its sister syndrome ${ }^{8}$. Other authors observed a high pain tolerance in $86 \%$ of children with chromosome $15 \mathrm{q}$ duplication syndrome ${ }^{9}$, and this clinical features is more evident in case of isodicentric mutations rather than in the interstitial forms in which the load of duplicate genes is less.

The purpose of this report was to document a case of a child affected by interstitial Cr4q del, expressing apparent pain insensitivity as singular feature, not previously described. Also, this report provides an opportunity to offer a discussion on genetic disorders featuring pain insensitivity/indifference. While all these disorders are exceptionally rare, they have provided great insight into the nociceptive system, as they represent models of functional 'knockout'. Consequently, studying these models of pain genetics could be also effective in order to reveal important targets for drug discovery ${ }^{10}$.

\section{Case report}

A 12-year-old Caucasian girl has been taken in care by the infantile neuropsychiatric team of the Maternal and Infant Health, Asl NA 3 SUD, Torre del Greco (Naples, Italy), since she was 3 years old. She came to our observation for a developmental delay as she was capable of achieving the head control at 7 months and the sitting posture at 15 months, whereas autonomous walking was not achieved until 23 months. In addition, the child manifested severe expressive language deficits, involving mainly the verbal language, rather than the sign language. She was born at term via spontaneous vaginal delivery, weighing $2,920 \mathrm{~g}$. The personal anamnesis showed that there were no perinatal asphyxia (APGAR score was 8 at 1 minute and 9 at 5 minutes). Brain magnetic resonance imaging revealed thinning of the corpus callosum. Other clinical features were horseshoe kidney, spina bifida occulta at L5 and S1 and facial dysmorphisms, including convergent strabismus of the left eye, mandibular hypoplasia, small nose, epicanthus. Examination of other systems showed no abnormality.
Psychic examination showed separation anxiety and impulse control disorders, such as trichotillomania and trichophagia. Full-scale intelligence quotient (IQ) was assessed by using Wechsler Preschool and Primary Scale of Intelligence (WPPSI). This test showed an IQ of 47 , suggestive of a moderate ID The patient receives a treatment program consisting in cognitive behavioral therapy, logotherapy and occupational therapy. Moreover, she underwent psychomotor education until she was 8 years old.

Family history was non-contributory as both parents had no family history of genetic diseases. Parents were healthy and unrelated and there was no history of miscarriage or infertility. Because of the presence of these multiple features a genetic analysis was performed. Patient's karyotype was reported as 46,XX,del(4), whereas the karyotypes of both parents were normal. Fluorescence in situ hybridization (FISH) documented a de novo hemizygous interstitial deletion on the long arm of the chromosome 4 between band q31.3 and q32.2 (Cr4 del q31.3 to q32.2). The deletion encompassed approximately $16.9 \mathrm{Mb}$.

Pain insensitivity. The parents referred that the child expressed no evidence of pain perception to injures which normally evoke pain, with minimal or absent grimacing or crying after falls, cuts or bruises. Consequently, there was severe disability caused by painless injuries, comporting various stove burns on legs and a right forearm bone fracture. These conditions were exacerbated by self-injurious behaviours consisting in excessive self-rubbing and scratching. The neurological examination manifested high pain threshold with preserved tactile sensitivity.

Written informed consent was obtained from the parents of the patient for publication of this case report.

\section{Discussion}

Chromosome 4 contains 1,000 to 1,100 genes and alterations in the number or structure of this chromosome can have a variety of effects, including delayed growth and development, ID, distinctive facial features, heart defects, and other medical problems. Nevertheless, at the data no other reports of alterations in pain sensitivity has been described.

A major limitation is the pain assessment in patients with ID and difficulties in communication. Pain can be assessed by observing physiological changes, such as breathing, blood pressure and heart rate, or behavioural changes, such as facial expressions, vocal expressions and body posture. In addition, pain assessment tools, such as the non-communicating children's pain checklist-Revised (NCCPC-R) or the revised-face, legs, activity, cry, consolability (r-FLACC) $)^{11}$ can be used. 
Despite of this, the difficulties in the assessment are numerous and they can lead to important implications for the treatment and recognition of the need for treatment in individuals with ID or any difficulties in communication and socialisation. For instance, although it is commonly assumed that reduced sensitivity to pain, or oversensitivity to pain, are more common in patients with Autism Spectrum Disorders ${ }^{12}$, however communication and social difficulties may make it difficult for these affected individuals to make theirdistress known and there is a greater likelihood that their pain may go unrecognised and untreated ${ }^{13}$. In our case, the pain insensitivity is clearly evident, manifesting itself as repeated and severe injuries associated with minimal or absent behavioral responses. Thus, this case can not be clinically interpreted as a case of alteration in pain expression with normal pain perception.

Among the genetic disorders involving mutations in genes encoding receptors, or modulators, expressing pain insensitivity there is the congenital insensitivity to pain with anhidrosis (CIPA) also referred to as hereditary sensory and autonomic neuropathy type IV (HSAN4). This rare disease is an autosomal recessive disease characterized by recurrent episodic fevers, anhidrosis, absence of reaction to noxious (or painful) stimuli, self-mutilating behaviors and $\mathrm{ID}^{14}$. The genetic basis of CIPA consists in a mutation in TRKA gene encoding the high-affinity tyrosine kinase receptor NTRK1 for nerve growth factor, and this gene is located on chromosome 1 (1q21-q22) ${ }^{15}$. A specific mutation in the NGF gene causes loss of pain perception and the HSAN5 phenotype. Carvalho et al. ${ }^{16}$ reported a family where five affected children had a congenital inability to feel pain, anhidrosis, defective temperature sensing, mild intellectual disability, and an immune deficiency, whereas other authors reported a family with a homozygous nerve growth factor mutation presented with congenital lack of pain appreciation, deficient temperature sensing and a lack of C-fibres, but normal sweating, immunity and cognitive abilities ${ }^{17}$. Probably, the HSAN5 phenotype is extended to encompass HSAN4-like characteristics, so either phenotypes could be parts of a phenotypic spectrum caused by changes in the nerve growth factor/TRKA signalling pathway. Moreover, both expresses identical peripheral nerve biopsy findings ${ }^{16}$. These phenotypes are so rare and well distinguishable by other hereditary sensory neuropathies like Familial dysautonomia or Riley-Day syndrome, which is an neurodevelopmental genetic autosomal recessive disorder, characterized by severe autonomic features including dysphagia, vomiting crises, blood pressure lability, sudomotor dysfunction, poor temperature, motor incoordination. In this disease patients also express relative indifference to pain $^{18}$.
In addition, many ion channel genes have been associated with human genetic pain disorders ${ }^{19}$ and several mutations in subunits of voltage-gated sodium channels (Navs) causing painful or painless clinical condition have been well studied ${ }^{20}$. Mutations in Nav1.8 channels, encoded by SCN10A, may contribute to painful peripheral neuropathy, whereas several mutations, causing the so-called 'channelopathy-associated insensitivity to pain'21, involve the channel Nav1.7 gene encoded by SCN9A, and the Nav1.9 encoded by SCN11A. Both Navs are primarily expressed in nociceptors, which are specialized peripheral sensory termination that work as key relay stations for the electrical transmission of pain signals from the periphery to the central nervous system. Recent genetic studies have identified Nav1.7 dysfunction in three different human pain disorders -i.e. primary erythermalgia, paroxysmal extreme pain disorder and channelopathy-associated insensitivity to pain or congenital 'indifference' to pain $^{22}$ - not necessarily featuring loss of pain sensitivity, but expressing more kinds of pain disorders. Depending on the function, Nav1.7 mutations can be divided in 'gain-of-function' mutations, causing primary erythermalgia and paroxysmal extreme pain disorder, and 'loss-of-function' Nav1.7 mutants which lead to congenital 'indifference' to pain. While in primary erythermalgia there is lowered threshold for activation and slowed deactivation involving pain attacks $s^{23}$ and erythema -particularly in the hands and feet- triggered by mild warming stimuli, paroxysmal extreme pain disorder is characterised by paroxysmal attacks of visceral pain involving the lower body (e.g., rectum and genitalia), or somatic pain of eyes, and jaw often accompanied by flushing of the affected site and other autonomic disturbances ${ }^{24}$. Over 20 different mutations causing primary erythermalgia have been discovered in Nav1.7, and almost all mutations investigated cause a hyperpolarizing shift of activation, allowing Nav1.7 to open at lower potentials compared with the wild type ${ }^{25}$. However, it is unknown why the pain episodes associated with primary erythermalgia mainly occur in the hands and feet. The genetic disorder of paroxysmal extreme pain disorder, previously known as familial rectal pain, is an autosomal dominant mutation in the SCN9A gene encoding for the alpha subunit of $\mathrm{NaV1.7}$. congenital 'indifference' to pain is caused by homozygous or compound heterozygous mutations in the SCN9A gene on chromosome 2q24. Individuals affected by congenital 'indifference' to pain have painless injuries beginning in infancy but otherwise normal sensory modalities. Perception of passive movement, joint position, and vibration are normal, as are tactile thresholds and light touch perception. Reflexes and autonomic responses are also normal. Congenital indifference' to pain is also characterized by an absence 
of nerve pathology on histologic examination and can be distinguished from hereditary sensory and autonomic neuropathies, such as HSAN4/CIPA or HSAN5, which are associated with pathologic changes in peripheral nerves.

The SCN11A is preferentially expressed in nociceptive neurons of dorsal root ganglia and trigeminal ganglia in which encodes Nav1.9 channel. The role of Nav1.9 channel in pain mechanisms is still under investigation, as Leipold et al. identified a specific de novo mutation in SCN11A in individuals with the congenital inability to experience pain who suffer from recurrent tissue damage and severe mutilations ${ }^{26}$, and its experimental deletion (Nav1.9-null) was shown either to diminish ${ }^{27}$, or had no effect ${ }^{28}$ on thermal pain hypersensitivity produced in knock-out mice. Nevertheless, it plays a key role in the generation of heat and mechanical pain hypersensitivity, both in subacute and chronic inflammatory pain models, suggesting that it may represent a suitable pharmacological target for inflammatory pain care. Moreover, Nav1.9 channel is also an important regulator of afferent sensitivity in visceral pain pathways to mechanical and inflammatory stimuli, so it could represent an important therapeutic target also for the treatment of visceral pain. A mutation in the gene has also been found in patients with congenital 'indifference' to pain, but in contrast to loss of function SCN9A mutations in this condition, SCN11A mutations are associated with a gain of function with sustained depolarisation of nociceptors impeding the generation of action potentials ${ }^{27}$.

Transient receptor potential (TRP) channels genes encode for several types of cation channels. Most TRP channels transport calcium, although some transport other cations such as sodium, magnesium, or iron. TRP channels are found in virtually every cell type in the body and hereditary diseases caused by defects in TRP genes have been described, including polycystic kidney disease and mucolipidosis type IV ${ }^{29}$. Some of the so-called 'thermosensitive' TRP channels, i.e. vanilloid 1 (TRPV1), ankyrin-repeat 1 (TRPA1), and melastatin 8 (TRPM8), play a key role in nociception ${ }^{30}$. Familial episodic pain syndrome is an autosomal dominant neurologic disorder characterized by onset in infancy of episodic debilitating upper body pain triggered by fasting, cold, and physical stress . It is caused by heterozygous mutation in the TRPA1 gene on chromosome $8 \mathrm{q} 13^{31}$. Other authors identified two gainof-function point mutations in SCN11A as the cause of another form of familial pain disorders, suggesting they can be causative of an autosomal-dominant episodic pain disorder 6 .

\section{Conclusion}

This clinical finding presents several particularities. Primarily this is the first report of pain insensitivity in a patient with a specific genetic deletion involving the interstitial region of the distal long arm of chromosome 4 . Moreover, as pain perception is a very complex physiological process involving several genes located on different chromosomes, and neural pathways, this report can serve as a useful model to better understand mechanisms of pain perception and its modulation.

Genetic basis for pain is a fascinating field of research and its study could represent a paramount weapon in the battle against pain, which is one of the most pervasive symptoms in clinical medicine. On the other hand, the pharmacological research on pain may provide the basis to develop a causative or symptomatic treatment for patients affected from these rare genetic disorders. Further investigations in this case are required to gain a better understanding of the genotype-phenotype correlation. This issue will be our next challenge.

\section{Ethical Responsibilities}

Protection of people and animals: The authors declare that no experiments were performed on humans or animals for this study.

Confidentiality of data: The authors declare that they have followed the protocols of their work center on the publication of patient data.

Privacy rights and informed consent: The authors have obtained the written informed consent of the patients or subjects mentioned in the article. The corresponding author is in possession of this document.

\section{Conflict of interests}

The authors have no financial or personal relationship which can cause a conflict of interest regarding this article. 


\section{References}

1. Rossi MR, DiMaio MS, Xiang B, et al. Clinical and Genomic Characterization of Distal Duplications and Deletions of Chromosome 4q: Study of Two Cases and Review of the Literature. Am J Med Genet A. 2009;149A(12):2788-94.

2. Ockey CH, Feldman GV, Macaulay ME, Delaney MJ. A large deletion of the long arm of chromosome No. 4 in a child with limb abnormalities. Arch Dis Child. 1967;42(224):428-34.

3. Sarda P, Lefort G, Fryns JP, Humeau C, Rieu D. Interstitial deletion of the distal long arm of chromosome 4. J Med Genet. 1992;29:259-61.

4. Lin AE, Garver KL, Diggans G, et al. Interstitial and terminal deletions of the long arm of chromosome 4: further delineation of phenotypes. Am J Med Genet. 1988;31:533-48.

5. Yakut S, Clarck OA, Sanhal C, et al. A familial interstitial $4 \mathrm{q} 35$ deletion with no discernible clinical effects. Am J Med Genet A. 2015;167A(8):1836-41.

6. Zhang XY, Wen J, Yang W, et al. Gainof-function mutations in SCN11A cause familial episodic pain. Am J Hum Genet. 2013;93(5):957-66.

7. Artigas-Pallarés J, Brun-Gasca C, Gabau-Vila E, Guitart-Feliubadaló M, Camprubí-Sánchez C. Aspectos médicos e comportamentais da síndroma de Angelman. Rev Neurol. 2005;41(11): 649-56.

8. Angulo MA, Butler MG, Cataletto ME. Prader-Willi syndrome: a review of clinical, genetic, and endocrine findings. J Endocrinol Invest. 2015;38:1249-63.

9. Luchsinger $\mathrm{K}$, Lau H, Hedlund JL, Friedman D, Krushel K, Devinsky O. Parental-reported pain insensitivity in Dup15q. Epilepsy Behav. 2016;55:124-7.

10. Goldberg YP, Pimstone SN, Namdari R, et al. Human Mendelian pain disorders: a key to discovery and validation of novel analgesics. Clin Genet. 2012;82:367-73.

11. Breau LM, Camfield CS, McGrath PJ, Finley GA. The incidence of pain in children with severe cognitive impairments. Arch Ped Adolesc Med.
2003;157:1219-26.

12. Messmer RL, Nader R, Craig KD. Brief report: judging pain intensity in children with autism undergoing venepuncture: the influence of facial activity. J Autism Dev Disord. 2008;38(7):1391-4.

13. Allely CS. Pain Sensitivity and Observer Perception of Pain in Individuals with Autistic Spectrum Disorder. ScientificWorldJournal. 2013;2013:916178. doi:10.1155/2013/916178.

14. Pérez-López LM, Cabrera-González M, Gutiérrez-de la Iglesia D, Ricart S, Knörr-Giménez G. Update Review and Clinical Presentation in Congenital Insensitivity to Pain and Anhidrosis. Case Rep Pediatr. 2015;2015:589852. doi:10.1155/2015/589852.

15. Indo Y. Genetics of congenital insensitivity to pain with anhidrosis (CIPA) or hereditary sensory and autonomic neuropathy type IV. Clinical, biological and molecular aspects of mutations in TRKA(NTRK1) gene encoding the receptor tyrosine kinase for nerve growth factor. Clin Auton Res. 2002;12 Suppl 1:I20-32.

16. Carvalho OP, Thornton GK, Hertecant J, et al. A novel NGF mutation clarifies the molecular mechanism and extends the phenotypic spectrum of the HSAN5 neuropathy. Journal of Medical Genetics. 2011;48(2):131-5

17. Einarsdottir E, Carlsson A, Minde J, et al. A mutation in the nerve growth factor beta gene (NGFB) causes loss of pain perception. Hum Mol Genet 2004;13:799805.

18. Norcliffe-Kaufmann L, Kaufmann H. Familial dysautonomia (Riley-Day syndrome): when baroreceptor feedback fails. Auton Neurosci. 2012;172(1-2):2630.

19. Lampert A, O’Reilly AO, Reeh P, Leffler A. Sodium channelopathies and pain. Pflugers Arch. 2010;460:249-63.

20. Bennett DL, Woods CG. Painful and painless channelopathies. Lancet Neurol. 2014;13(6):587-99.

21. Cox JJ, Reimann F, Nicholas AK, et al. An SCN9A channelopathy causes congenital inability to experience pain. Nature.

2006;444(7121):894-8.

22. Drenth JPH, Waxman SG. Mutations in sodium-channel gene SCN9A cause a spectrum of human genetic pain disorders. J Clin Invest. 2007;117(12):3603-9.

23. Cregg R, Laguda B, Werdehausen R, et al. Novel Mutations Mapping to the Fourth Sodium Channel Domain of Nav1.7 Result in Variable Clinical Manifestations of Primary Erythromelalgia. Neuromolecular Med. 2013;15(2):265-78.

24. Fertleman CR, Baker MD, Parker KA, et al. SCN9A mutations in paroxysmal extreme pain disorder: allelic variants underlie distinct channel defects and phenotypes. Neuron. 2006;52(5):767-74.

25. Eberhardt M, Nakajima J, Klinger AB, et al. Inherited pain: sodium channel Nav1.7 A1632T mutation causes erythromelalgia due to a shift of fast inactivation. J Biol Chem. 2014;289(4):1971-80.

26. Leipold E, Liebmann L, Korenke GC, et al. A de novo gain-of-function mutation in SCN11A causes loss of pain perception. Nat Genet. 2013;45(11):1399-404.

27. Priest BT, Murphy BA, Lindia JA, et al. Contribution of the tetrodotoxin-resistant voltage-gated sodium channel nav1.9 to sensory transmission and nociceptive behavior. Proc Natl Acad Sci U S A. 2005;102:9382-7.

28. Leo S, D'Hooge R, Meert T. Exploring the role of nociceptor-specific sodium channels in pain transmission using nav1.8 and nav1.9 knockout mice. Behav Brain Res. 2010;208:149-57.

29. Moran MM, McAlexander MA, Bíró T, Szallasi A. Transient receptor potential channels as therapeutic targets. Nat Rev Drug Discov. 2011;10(8):601-20.

30. Sałat K, Filipek B. Antinociceptive activity of transient receptor potential channel TRPV1, TRPA1, and TRPM8 antagonists in neurogenic and neuropathic pain models in mice. J Zhejiang Univ Sci B. 2015;16(3):167-78.

31. Kremeyer B, Lopera F, Cox JJ, et al. A gain-of-function mutation in TRPA1 causes familial episodic pain syndrome. Neuron. 2010;66(5):671-80. 